\author{
Cadernos de \\ ESTUDOS LINGUIISTICOS - (59.2), Campinas, pp. 439-459 - mai./ago. 2017
}

\title{
FIGURAS DE RETÓRICA NO DISCURSO ECONÔMICO PARA NARRAR A CRISE MUNDIAL DE 2008
}

\author{
THIAGO MARTINS PRADO* \\ (UNEB)
}

\begin{abstract}
RESUMO: O estudo aborda três narrativas científicas sobre a recente crise econômica mundial com o intuito de reconhecer a importância das figuras de linguagem ou da própria narração literária como recurso a reforçar as teses econômicas discutidas. Os exemplos apresentados são: a) a alegoria dos cisnes negros, de Nassim Nicholas Taleb; b) a contaminação metonímica da crise econômica antevista por Hyman P. Minsky; e c) a tradução hiperbólica da teoria do estoque monetário, por William T. Still e Peter Joseph. A relevância de investigar tais narrativas dá-se pelo fato de se constituírem como versões de partida bastante recorrentes para a compreensão sobre o colapso financeiro de 2008 nos meios acadêmicos ou nos meios de ativismo econômico mais radical. O objetivo do artigo dedicase a analisar esses discursos econômicos observando-se a figura de linguagem como um recurso a estabelecer a composição do argumento e a ampliar o poder de persuasão de tais discursos. Ao se basear nos estudos de Fiorin (1998 e 2016), Jakobson (2003), Kothe (1986) e Perelman e OlbrechtsTyteca (2005), o artigo aponta como as estratégias da retórica são importantes para a construção do saber na área da Economia.
\end{abstract}

Palavras-chave: Figuras de Retórica e Economia. Crise Econômica. Linguagem Literária na Economia.

\begin{abstract}
The study approaches three scientific narratives about the recent global economic crisis in order to recognize the importance of figure of speech or even the literary narration as a resource to strengthen the economic theses discussed. The examples provided are: a) the allegory of the black swans of Nassim Nicholas Taleb; b) the metonymic contamination of the economic crisis envisioned by Hyman P. Minsky; c) the hyperbolic translation of the theory of money supply, by William T. Still and Peter Joseph. The relevance in order to investigate such narratives is because they are versions in order for us to comprehend about the financial collapse in 2008 at academic settlement of most radical economic activism. The objective of this study is to analyze these economic discourses by observing the figure of speech as a resource to establish the composition of the argument and to extend the power of persuasion. Based on the studies of Fiorin (1998 and 2016), Jakobson (2003), Kothe (1986) and Perelman and Olbrechts-Tyteca (2005), the article points out how the strategies of rhetoric are important for the construction of knowledge in the area of Economy.
\end{abstract}

Keywords: Figures of speech and Economy, Economic crisis, Literary language in Economy.

*minotico@yahoo.com.br 


\section{INTRODUÇ̃̃O}

Depois de passados cinco anos da crise financeira que afetou uma série de mercados em 2008, Henry Paulson, o secretário do Tesouro dos Estados Unidos daquele momento, considerando o grau de interligação, de internacionalização e a atmosfera e as práticas que, conjuntamente, interferem nas unidades financeiras ao mesmo tempo, utilizou-se da alegoria do efeito pipoca para combater a outra alegoria do efeito dominó, ${ }^{1}$ já proliferada pela mídia norte-americana. ${ }^{2}$ Nessa declaração, nota-se que a figura de linguagem, muito além de servir como um mecanismo de tradução do discurso econômico para a norma padrão da língua, indica uma especificidade de raciocínio que transfere as interpretações demarcadas de intenções ou de posições socioculturais acerca dos fenômenos econômicos para uma imagem de forte representação, que, muitas vezes, escamoteia os interesses do enunciador. Paulson, no âmbito do documentário Hank, dirigido por Joe Berlinger (2013), ao substituir a alegoria da peça de dominó que inicia o toque de quedas em sequência pela alegoria do estouro das pipocas em uma panela, pulveriza a investigação da responsabilidade da crise financeira quando reforça a mutualidade sistêmica das unidades econômicas.

Ainda que, com o colapso financeiro de 2008, diversos exemplos de figuras de linguagem tenham surgido para explicar o que os modelos econômicos predominantes não puderam prever, é preciso reconhecer que a apropriação dessas figuras para a operacionalização do discurso econômico não é um fenômeno contemporâneo. A alegoria mais comentada pela história econômica está logo no início do liberalismo, com o fundador da economia clássica, Adam Smith, e, de certo modo, reverbera até hoje em conceitos mais técnicos de autorregulação do mercado. A mão invisível, de Smith (2013), preenche uma lacuna no discurso técnico sobre a razão de independência de regulação para as economias e, de forma simultânea, torna mais eficiente a linguagem figurada como elemento compositivo do discurso econômico (com forte poder de representação e entendimento).

${ }^{1} \mathrm{O}$ conceito de alegoria é entendido como uma imagem concreta para representar um conceito abstrato, como um signo de substituição mais forte que a metáfora, que utiliza um terceiro elemento (ou qualidade) para aproximar dois outros elementos. Tal definição foi retirada da descrição de conceitos de alegoria da pesquisadora Glória Palma, na entrevista Leituras de O médico e o monstro: alegoria e metáfora.

${ }^{2}$ Enquanto a alegoria do efeito dominó sugere que o colapso financeiro de 2008 teve um ponto originário causal que determinou uma sequência de quedas na economia norte-americana, como se fossem peças de dominó montadas, a alegoria do efeito pipoca sugere que ocorreu um aquecimento multilateral que pressionou todas as instituições financeiras e que as fez estourar conjuntamente devido ao seu forte grau de interligação. Um dos momentos em que Henry Paulson defende a alegoria do efeito pipoca pode ser visto no documentário Hank: cinco anos depois do colapso (2013), dirigido por Joe Berlinger. 
Três exemplos de narrativas científicas econômicas que utilizaram artifícios literários para explicar ou para antecipar a crise financeira mundial iniciada em 2008 foram descritos nesse estudo, considerando-se tanto o valor compositivo da figura de linguagem eleita para a montagem do conceito no discurso econômico como também o comprometimento ideológico que tal recurso literário sugere. Na primeira parte do artigo, a alegoria do cisne negro, de Nassim Nicholas Taleb (2008), foi revisada como uma crítica ambígua ao sistema de previsão econômica de larga escala e à epistemologia contemporânea. Na segunda parte, a partir das análises de Hyman Minsky (2009), observou-se como a contaminação metonímica da economia pelas unidades especulativas ou pelas unidades Ponzi foram derivadas, principalmente, das políticas de empréstimos alimentadas pelas instituições financeiras. ${ }^{3} \mathrm{Na}$ terceira parte, verifica-se como o recurso da hipérbole em relação aos estudos de Milton Friedman (1978) sobre a teoria do estoque monetário denota ser a ferramenta discursiva mais adequada que os ativistas da área econômica William T. Still (1996), com o documentário The money masters, e Peter Joseph (2007, 2008 e 2011), com a trilogia Zeitgeist, reconheceram para explicar uma inevitável crise financeira em meio à atmosfera paradoxal da pressão inflacionária, do estímulo desenfreado ao consumismo e do risco de escassez de capital para o indivíduo contemporâneo.

A importância da escolha dessas narrativas científicas orientou-se pela capacidade de generalização que assumiram depois de estourada a crise financeira mundial originalmente advinda da elevação do não pagamento dos Collateralized Debt Obligations (CDOs). ${ }^{4}$ A narrativa científica de Taleb e a de Minsky tornaram-se as primeiras versões de larga escala a serem utilizadas entre os meios acadêmicos na tentativa de interpretar a crise financeira de 2008. Interessante notar o poder de antecipação e de complementaridade desses estudos: enquanto Minsky publicou o artigo A hipótese da instabilidade financeira, no início dos anos de 1990, relatando os riscos da economia quanto às práticas oriundas dos regimes de financiamento, Taleb realizou a publicação do seu livro A lógica dos cisnes negros em 2007, comentando, dentre outras considerações sobre a incerteza como campo epistemológico, a exposição que modelos financeiros promovem aos investidores ao menosprezarem a improbabilidade de movimentos extremos. As narrativas científicas de Still e de Joseph, por outro lado, propagaram-se nos grupos de ativismo econômico mais radical. Por buscarem uma distribuição maior de seus discursos, tanto Still, em 1996, com The money masters, como Joseph, em 2007, em 2008 e

\footnotetext{
${ }^{3}$ São consideradas especulativas as unidades financeiras que sustentam o pagamento das dívidas dos empréstimos pela conta de rendimentos e que não conseguem pagar o principal do passivo com os fluxos de caixa. São consideradas Ponzi as unidades financeiras que não possuem capital suficiente para pagar o principal da dívida e os juros oriundos dela.

${ }^{4}$ Instrumentos financeiros que captam dinheiro emitindo obrigações próprias, antes de investi-lo em um misto de ativos, como empréstimos. Os CDOs que promoveram o colapso da economia norte-americana e mundial formaram-se como um misto de dívidas imobiliárias de alto risco com outras dívidas de baixo risco, como certificados do Tesouro dos EUA.
} 
em 2011, com a trilogia do movimento Zeitgeist, apostaram mais no suporte do vídeo e, posteriormente, atrelaram a sua reprodução às ferramentas da internet. Ambos se utilizaram de uma interpretação peculiar da teoria monetarista de Milton Friedman para denunciar o controle das corporações financeiras nos governos e nos cidadãos e sugeriram atitudes bem distantes do funcionamento das organizações institucionais vigentes na área econômica, como a extinção do Fed (Still) ou a eliminação da prática monetária (Joseph).

A pertinência teórica em realizar uma investigação das figuras de linguagem no discurso econômico justifica-se de dois modos. No primeiro plano, a proposição de se analisar a formação do argumento em narrativas científicas por meio da realização das figuras de linguagem, demasiadamente ilustradas nos textos poéticos, está em consonância com as exigências advindas da própria área dos Estudos de Linguagem. Na perspectiva de Jakobson (2003, p.129): “o estudo linguístico da função poética deve ultrapassar os limites da poesia". De outro modo, atentando-se às observações de Chaïm Perelman e Lucie Olbrechts-Tyteca (2005), a tendência em enfatizar meramente o lado estilístico dessas figuras, não as concebendo como recursos a constituírem a própria argumentação arquitetada no texto, deve-se a um isolamento da figura em relação ao seu contexto. Portanto, no entender desses autores, a investigação sobre as figuras de linguagem devem atender menos as necessidades de legitimação de um modo literário de expressão que as emergências em reconhecê-las como técnicas do discurso persuasivo. Nesse ponto, Olivier Reboul (2001, p.113) conceitua a figura de linguagem reconhecendo sua finalidade expressiva, persuasiva ou estética como uma estratégia retórica: "qualquer tipo de recurso ou manipulação da linguagem com fins persuasivos, expressivos ou estéticos com o objetivo de ampliar o significado ou a ênfase que o orador quer imprimir em seu discurso".

No segundo plano, ao notar a figura de linguagem como técnica de persuasão, podem-se interpretar teorias científicas como montagens discursivas e questionar a sua legitimidade ou a sua presunção em implicar autonomia ou fundamentos inquestionáveis para as áreas de saber. Nesse sentido, reconhecer o discurso econômico como um entrecruzamento de narrativas eivadas de ferramentas e estratégias de persuasão desmobiliza a nocividade (ou a confiança) de uma interpretação mais monolítica ou mais hegemônica sobre os fenômenos econômicos. Como exemplo recente de como pode ser perigoso o não reconhecimento do saber econômico como uma prática discursiva repleta de técnicas ou estratégias de persuasão, Paul Krugman (2009) - ganhador do Nobel de Economia de 2008 - relata que a interpretação hegemônica sobre o conceito de eficiência dos mercados acarretou uma cegueira generalizada na maioria dos economistas a respeito da possibilidade de surgimento de uma das maiores bolhas financeiras da história, ao mesmo tempo em que tal interpretação possibilitou exponencialmente inflar essa mesma bolha. 


\section{O USO DA ALEGORIA POR NASSIM NICHOLAS TALEB ${ }^{5}$}

Na visão de Taleb (2008), as previsões governamentais ou corporativas de larga escala, por meio de uma estrutura de conhecimento firmemente institucionalizada e de poder, causam mais danos à sociedade que criminosos. Como ensaísta da incerteza, Taleb afirma que as previsões de larga escala aparecem como atalhos, ou melhor, como trapaças - a matemática aparentemente perfeita dos grafistas, por exemplo, é uma distorção da economia real, uma falsificação que justifica a direção dos investimentos. O engodo institucional da formação de previsões de larga escala desconsidera, inicialmente, os efeitos multiplicativos não lineares, que tendem a complexificar a dinâmica dos cálculos por cada movimento traçado em forma de estágios alternativos e múltiplos. Além disso, no entendimento de Taleb, tais previsões menosprezam o campo das incertezas advindas da escolha ou do impulso humanos como fatores subjetivos de variação.

A marca mais importante dos estudos da incerteza por Taleb remete para a discussão de um fenômeno que ele chama de cisne negro, uma alegoria que traduz a soma de três características para determinados eventos analisados no campo da incerteza: a) a raridade - não há, no passado, dados que apontem para a sua possibilidade; b) a capacidade de impactar extremamente comunidades - o inesperado na coletividade causa uma comoção generalizável; e c) o potencial de incitar previsibilidades retrospectivas - as narrativas apenas se dão para os eventos dessa ordem após os seus acontecimentos, ajustando-se o sistema de previsões ao anteriormente não narrado. Como recurso retórico e chave de leitura de A lógica do cisne negro, essa alegoria é apresentada por Taleb já nas primeiras linhas do seu escrito.

Antes da descoberta da Austrália, as pessoas do Antigo Mundo estavam convencidas de que todos os cisnes eram brancos. Esta era uma crença inquestionável por ser absolutamente confirmada por evidências empíricas. Deparar-se com o primeiro cisne negro pode ter sido uma surpresa interessante para alguns ornitólogos (e outras pessoas extremamente preocupadas com a coloração dos pássaros), mas não é aí que está a importância dessa história. Ela simplesmente ilustra uma limitação severa no aprendizado por meio de observações ou experiências e a fragilidade de nosso conhecimento. Uma única observação pode invalidar uma afirmação originada pela existência de milhões de cisnes brancos. Tudo que se precisa é de um único pássaro negro (que também, pelo que sei, é muito feio) [...] Primeiro, o Cisne Negro é um outlier, ${ }^{6}$ pois está fora do âmbito das expectativas comuns, já que nada no passado pode apontar convincentemente para a sua possibilidade. Segundo, ele exerce um impacto extremo. Terceiro, apesar de ser um outlier, a natureza humana faz com que desenvolvamos explicações para sua ocorrência após o evento, tornando-o explicável e previsível. (TALEB, 2008, p.15-16)

\footnotetext{
${ }^{5}$ Consultar nota 1 para conceito de alegoria.

${ }^{6}$ Valor atípico em uma amostra estatística.
} 
No decorrer dessa publicação, entre a declaração da falibilidade dos sistemas de previsão e a interpretação dos cisnes negros, Taleb propõe uma investigação, de um certo ângulo, das recentes crises econômicas. Segundo Taleb, a fusão das instituições bancárias em números cada vez mais reduzidos impõe a mudança de uma política variada de empréstimos para um sistema de concessão de crédito mais homogêneo e hegemônico - o que pode sugerir menos crises, no entanto mais sérias, mais globais e mais impactantes quando ocorrerem.

Partindo dessa perspectiva, a interpretação das crises econômicas recentes como cisnes negros é repleta de ambiguidades. Por um lado, Taleb transfere parte da responsabilidade do sistema bancário para a epistemologia hodierna; o ensaísta, tão determinado por mapear e elevar a descoberta dos cisnes negros, transforma a crise econômica num problema de desajuste do entendimento da realidade, por desconsiderar a aleatoriedade e apostar na simplificação dos métodos de previsão. Por outro lado, por exatamente apontar o conjunto de previsões como uma falsificação matemática, Taleb fornece pistas para se conceber as fórmulas e os cálculos das previsões das instituições financeiras como uma estratégia para o agrupamento de capital por meio meramente da força institucional do discurso técnico. Ainda que falho e simplificando a realidade, o discurso técnico de previsão econômica, por si só, é um ativo interessante a agregar valores às instituições financeiras - ele, por atender, ao mesmo tempo, o requisito da inovação para seduzir investidores e a consistência validada por centros especializados do saber, torna-se uma propaganda a substituir o próprio produto.

$\mathrm{Na}$ investigação sobre o campo da incerteza, Taleb apresenta o entendimento sobre a fragilidade dos sistemas de previsão ao mesmo tempo em que produzem um forte magnetismo nos compradores/investidores através do seu uso como rotulagem ou publicidade. A sedução dessa propaganda hipnótica fomenta expectativas que contagiam uma massa de compradores/investidores, e essa própria atmosfera também exponencializa a função publicitária dos previsores econômicos, também determinando os modos de cálculos futuros das previsões para continuar aumentando ou, no mínimo, preservando o número dos clientes crentes nos sistemas de previsão econômica de larga escala.

Como já afirmado pelo filósofo da incerteza, a simplificação dos modelos de previsão de larga escala da economia implica danos generalizáveis. Taleb elenca os efeitos devastadores dos cisnes negros concomitante à descrição da invalidez dos sistemas de previsão de larga escala: a falta de investigação sobre a aleatoriedade torna a raridade dos eventos um perigo e potencializa os impactos dos cisnes negros.

Taleb indica que os problemas relacionados aos cisnes negros pertencem, predominantemente, ao campo epistemológico, mais diretamente, à fragilidade das teorias de conhecimento que não abarcam a casualidade. A partir da alegoria do cisne negro, o teórico da incerteza Taleb evade da ideia de controle total dos trâmites socioeconômicos organizada por uma macroestrutura eficiente e inteligente e ataca a desinteligência e a irrealidade dos sistemas de previsão de larga escala. No entanto, no que há de negativo na lógica dos cisnes negros está a discussão focada na reforma da epistemologia sobre o impacto dos fatos altamente improváveis - o que isenta, parcialmente, a responsabilidade social das macroorganizações financeiras e do Estado, alterando os papéis de eficientes produtores para os de negligentes interpretadores das crises. 
A alegoria do cisne negro inicialmente denuncia a interpretação dos mercados eficientes como uma estratégia pertencente a uma formação ideológica dominante sobre a economia (que pode e deve ser questionada). Entretanto, posteriormente, essa mesma alegoria parece aliviar a responsabilidade dos grupos dessa formação ideológica quanto à crise ao se concentrar na proposição de uma nova metodologia de análise de risco. Essa ambiguidade promovida no campo da análise econômica pela alegoria de Taleb ainda se preserva quando se investe na relação entre análise econômica e análise linguística.

Partindo-se das considerações de Fiorin (1998) - de que todo discurso é uma citação de outro já existente e de que essa relação interdiscursiva pode se dar de forma polêmica, como em uma arena de conflitos, ou de uma forma contratual, como em um palco de acordos -, é certo dizer que a alegoria do cisne negro surge polêmica e consolida-se contratual. A alegoria de Taleb desmonta a alegoria da mão invisível, de Smith, que organizava conceitos e práticas hegemônicos para a economia como uma estratégia discursiva dos grupos ideologicamente dominantes com o intuito de promover a ideia de eficiência nos mercados. Nesse instante, a polêmica instaura-se entre esses discursos. Porém, depois que o colapso financeiro ocorreu em 2008, a ação de repensar uma nova forma de compreender e de analisar os mercados sobrepõe-se sobre a nomeação e a punição dos agentes financeiros que inflaram de bolhas a economia. Nesse momento, a alegoria do cisne negro estabelece-se como um contrato que protege os interesses dos mesmos grupos sociais que antes possuíam um entendimento da economia oposto à proposição de Taleb.

Tendo-se em consideração o conceito e a função social da alegoria segundo Flávio R. Kothe (1986), a figura de linguagem de Taleb confirmase mais uma vez como um recurso ideologicamente dual. Ainda que se deva compreender a alegoria como uma representação concreta de uma ideia abstrata, é preciso atentar à declaração do estudioso Kothe (1986, p.21) sobre essa figura de linguagem: "a alegoria nunca é apenas um dado coletivo, mas um estratégico instrumento ideológico". Para Kothe, as alegorias tendem, em predominância, a ser mais utilizadas em seu aspecto mais convencional, autoritário e repressor, como figuras que reiteram a ideologia dos grupos economicamente privilegiados. Novas alegorias que desafiem essa lógica de apoio às classes dominantes, conforme o teórico de literatura, somente se possibilitam a partir do desvelamento da prática convencional da alegoria e da incitação da alteridade em novo plano alegórico. Desvelar a alegoria é reconhecer as respostas armadas nas cenas de tensões entre classes sociais; incitar a alteridade é promover uma versão alternativa que se ocultou por causa da hegemonia interpretativa veiculada pelos grupos ideológicos dominantes. A partir desses ensinamentos, é certo argumentar que a alegoria do cisne negro desvela e cerca a versão da alegoria da mão invisivel, comprometendo o seu funcionamento, ao revelar as suas estratégias discursivas e os seus defeitos de análise da economia. Concomitantemente, a alegoria do cisne negro realiza uma alternativa desviante e subterrânea às formações discursivas dos grupos ideológicos dominantes. Por esse prisma, a alegoria de Taleb é enfatizada 
como uma forma de contestação social. Quando a alegoria do cisne negro é apropriada pelos grupos dominantes com a intenção de isentar responsabilidades e dispersar a nomeação dos culpados, o seu poder de desvelar declina e o de camuflar intenções sociais eleva-se. Nesse ponto, a alegoria de Taleb reproduz a manutenção de uma ordem social. Esse movimento da alegoria do cisne negro evoca, em perfeição, a oposição que Kothe propõe entre leitura alegórica (que desmascara interesses) e alegorização (que disfarça interesses).

\section{O USO DA METONÍMIA POR HYMAN MINSKY ${ }^{7}$}

No capítulo cinco de A teoria geral do emprego, do juro e da moeda, John Maynard Keynes (1982) esclarece como a formação de expectativas na economia, imbuída de inevitável mecanismo de previsões, não só determina preços de venda de produtos a curto prazo e política de custos por meio de compras de produtos ou serviços a longo prazo, como também interfere no próprio volume de emprego ofertado pelas empresas. Além disso, Keynes apresenta como o estado das expectativas é volátil, afirmando que ele pode ser modificado por variações contínuas. No entender de Keynes, as previsões, no geral, baseiam-se nos resultados mais recentes das empresas desempenhando um papel predominante na formulação de expectativas; ademais, o economista sinaliza que expectativas a longo prazo surgem atreladas a revisões imprevistas.

Embora Keynes tenha desenvolvido um argumento que ilustra como a articulação entre previsões e expectativas influencia o número de empregos, em 1936, a sua discussão estava mais centrada na análise dos fluxos de caixa das empresas. Mais tarde, seria Minsky (2009) que atualizaria a discussão sobre como a lógica dos sistemas de previsões e da consequente fabricação de expectativas articula-se aos mercados.

$\mathrm{Na}$ perspectiva de Minsky, em seu artigo A hipótese da instabilidade financeira, na atualidade, a análise das relações financeiras, por meio do mecanismo diverso de previsões, suplanta as obrigações das empresas e de seus fluxos de caixa. Em consequência disso, as expectativas de lucro determinam os fluxos de financiamento e o preço de mercado desses contratos de financiamento. É baseado nessas expectativas que as unidades financeiras na esfera da micro à macroeconomia são criadas, gerenciadas e estudadas no âmbito de uma política de empréstimos. Para não escapar das ilustrações de Minsky, podem ser citados: as famílias com seus cartões de crédito; os governos com seus débitos custeados e com flutuação; ou ainda as unidades transnacionais como reflexos de um sistema financeiro internacionalizado.

${ }^{7} \mathrm{O}$ conceito de metonímia como uma figura de linguagem que permite um deslocamento de significado pela relação de contiguidade foi retirado de Sílvia Regina Pinto (2005). 
Em meio à investigação sobre as unidades financeiras que captam financiamento, Minsky estabeleceu uma classificação em três tipos: unidades hedge, unidades especulativas e unidades Ponzi. Denominam-se de hedge as unidades que preservam suas obrigações de contrato de pagamento com os próprios fluxos de caixa; chamam-se de especulativas as unidades que sustentam o pagamento das suas dívidas dos empréstimos por meio de sua conta de rendimentos, mas que não conseguem pagar o principal do passivo com seus fluxos de caixa; intitulam-se de Ponzi as unidades que não possuem capital suficiente para pagar o principal da dívida e os seus juros. Enquanto, na hedge, o financiamento pode ser garantido com o capital próprio da unidade, na especulativa, novas dívidas podem ser emitidas para a rolagem de dívidas anteriores e, na Ponzi, a venda dos ativos e o aumento da dívida pela retirada de mais empréstimos para pagamento de juros comprometem os rendimentos futuros dessa unidade.

A partir dessa classificação, o economista desenvolve a sua hipótese de instabilidade financeira baseada no agigantamento das unidades especulativas e das Ponzi. No primeiro princípio, Minsky afirma que os regimes de financiamento podem gerar instabilidade na economia; no segundo princípio, ele apresenta $o$ argumento de que, depois de períodos de equilíbrio e prosperidade, a economia tende a transitar para relações financeiras que assumem riscos maiores e favorecem o desequilíbrio. É nesse ponto dos seus argumentos que Minsky faz uso da metonímia para explicar a mudança da economia dos quadros de estabilidade para os de instabilidade.

Admitindo que as unidades financeiras componham partes do sistema de empréstimos e que essas mesmas possam ser responsáveis pela crise na economia - tal qual Minsky descreveu em seus princípios -, o colapso financeiro pode ser resultado da redução das unidades hedge e do contágio e crescimento de unidades especulativas e Ponzi no sistema de financiamento. O recurso da metonímia serve para explicar como partes (unidades) que sugerem riscos aos empréstimos elevam-se a tal ponto que acabam por abarcar a própria proteção do sistema financeiro.

Pode ser demonstrado que se o financiamento hedge predomina então a economia pode muito bem ser um sistema que tende ao equilíbrio e o mantém. Em contraste, quanto maior o peso das finanças especulativas e Ponzi, maior a probabilidade da economia ser um sistema amplificador de desvios. O primeiro teorema da hipótese de instabilidade financeira é que a economia tem regimes de financiamento que a tornam estável e regimes de financiamento que a tornam instável. O segundo teorema da hipótese de instabilidade financeira é que, ao longo de períodos de prosperidade prolongada, a economia transita das relações financeiras que contribuem para um sistema estável para relações financeiras que contribuem para um sistema instável. (MINSKY, 2009, p.318-319)

A metonímia, a figura de linguagem utilizada por Minsky, é caracterizada como uma associação semântica por meio da contiguidade de significados entre dois elementos; ela consiste, nesse sentido, em uma substituição de um nome por outro por causa de uma relação semântica extrínseca. Atentando-se aos estudos de Lakoff e Johnson (2002) sobre a metonímia, nota-se que essa função referencial, que permite o uso de uma entidade para a representação de outra, não 
ocorre aleatoriamente, mas como um conceito sistemático. Ao declarar os tipos de financiamento, Minsky desloca as titulações dadas às unidades financeiras - como hedges, especulativas ou Ponzi - para os próprios regimes de empréstimos. Aqui o uso da metonímia faz deslizar, na ordem das finanças, a classificação das unidades para as transações, gerando uma atividade linguística que permite conceituar diferentes formas de financiamento. Ademais, Minsky observa como os tipos de financiamento, advindos de práticas recorrentes, podem sobrepor-se às próprias relações financeiras (equilibrando-as ou desestabilizando-as). Na hipótese de Minsky, a predominância de regimes de financiamento hedge, com o passar dos anos de uma economia de prosperidade, levam as instituições a alimentar o risco e a agregar, cada vez mais, os financiamentos especulativos ou Ponzi, retirando os limites e a nitidez que anteriormente poderiam separar cada um deles. No caso da crise econômica de 2008, é interessante notar que o alargamento da aceitação institucional de tipos metonímicos específicos de regime de financiamento (especulativos ou Ponzi), tornando-os operações-padrões, "invisibilizou” a especificidade e a qualidade de todos os regimes e impediu enxergar a nocividade para as relações financeiras.

Ao se entender a metonímia como um deslocamento de referência cujo efeito é produzido por sua direção, presume-se, como comenta Pinto (2005), que a sucessão de deslocamentos pode imprimir uma visão particularizada da realidade. Concebendo que o contágio metonímico nos regimes de financiamento aponta para um desvio de referência e para uma apresentação singular da realidade econômica que deforma a análise de finanças, é possível argumentar que o sentido negativo atribuído às titulações de especulativas ou de Ponzi às unidades financeiras, quando tais titulações foram transladadas aos regimes de financiamento, pode ter-se enfraquecido ou ainda pode ter sido entendido como um conceito que define elementos necessários à área de investimento a gerar ativos vendáveis quando misturados a outros ativos, como em CDOs. Nesse sentido, os regimes de financiamento especulativos ou Ponzi foram compreendidos como instrumentos de composição importantes para a multiplicação de produtos bancários. O deslocamento de representação ocasiona também um desvio semântico nocivo: o risco é, portanto, traduzido como investimento (e elogiado).

O momento Minsky, dessa forma, foi uma antecipação dos motivos que acarretaram a crise financeira iniciada nos EUA em 2008 - em que um número grande de unidades especulativas, por escassez monetária e sofrendo com as bolhas inflacionárias, transforma-se em Ponzi e as unidades Ponzi perdem o patrimônio líquido. Nesse momento, tais unidades, com baixa liquidez, tentam vender ativos por valores cada vez menores a fim de se capitalizarem. Entretanto os que possuem capacidade de adquirir esses ativos recusam-se a comprá-los pelo fato de a deflação dos preços deles continuar.

Ao avaliar os contextos da recente crise econômica dos Estados Unidos, à luz dos estudos de Minsky sobre a instabilidade financeira, o comentarista Conceição (2009) destaca dois eventos que, de forma integrante, impulsionaram a desestabilidade na economia norte-americana. Por um lado, a ascensão das 
teorias econômicas neoclássicas por parte considerável dos analistas de mercado estimulou a criação de um sistema financeiro que, embora interdependente e interligado, possuía a vulnerabilidade de ser escassamente regulado. Por outro lado, a abertura dos mercados financeiros globalizados às ferramentas tecnológicas das telecomunicações permitiu a entrada indiscriminada de um otimismo cego ao mesmo tempo em que estratégias extremamente arriscadas foram testadas no mercado de capitais a elevar preços de ações a níveis preocupantes.

$\mathrm{Na}$ investigação de Conceição, boa parte das instituições financeiras, comandada pelo modelo dos Estados Unidos de desregulação, estabeleceu uma estratégia que enfraqueceu conjuntamente o sistema de finanças como um todo. Os agentes financeiros mais fortes retiraram crédito barato para alimentar bolhas especulativas e para agrupar entradas e saídas no mercado de capitais com agentes de igual estatura - o que gerou prejuízos consideráveis em players mais fracos, tornando o mercado financeiro gradativamente mais concentrado e, concomitantemente, o sistema de interdependência mais vulnerável. Para Conceição, nessa conjuntura, o adiamento do colapso financeiro e da multiplicação contagiosa de unidades Ponzi deu-se meramente enquanto a geração de expectativas de aquecimento econômico dava-se de forma artificial através da existência de bolhas inflacionárias.

Tal manobra no mercado de capitais acabou desoxigenando as áreas de investimento e cercando as instituições com um alto grau de nocividade especulativa. O que antes pareceu ser uma fórmula de aceleração e desenvolvimento do mercado sob uma perspectiva de saudável desregulação trouxe seus frutos podres a contaminar, cada vez mais, os outros na mesma cesta.

\section{O USO DA HIPÉRBOLE POR WILLIAM T. STILL E PETER JOSEPH ${ }^{8}$}

Quando Milton Friedman (1978) explicou o fenômeno da inflação por meio de sua teoria do estoque monetário, a maior preocupação do economista era sugerir estratégias de controle da emissão da moeda a fim de propiciar políticas de ajustamento, no sentido de debelar ou prevenir a toxicidade inflacionária para o sistema econômico. Nesse sentido, Friedman traduziu as tendências inflacionárias considerando, centralmente, que tal fenômeno deriva da emissão da moeda nos níveis acima da velocidade da circulação monetária. Friedman atenta para o fato de que a variação na velocidade da circulação da moeda acontece determinada pelas expectativas de baixa ou de aumento de preços. $\mathrm{Na}$ perspectiva de decréscimo, a velocidade de circulação diminui, ocorrendo maior retenção de capital, já que o dinheiro constitui-se em um bem que se valoriza frente a mercadorias e serviços no decorrer do tempo. A contenção e posse da

${ }^{8} \mathrm{O}$ conceito de hipérbole como uma figura que amplia, demasiada ou defeituosamente, um determinado objeto, sentimento ou ideia, de forma a provocar no indivíduo estranheza para além da realidade crível ou padrão foi retirado de Carla Escarduça (2005). 
moeda, nesse caso, dão a impressão de garantia, no futuro, de um gasto mais consolidado em um bem significativo ou de uma proteção financeira maior para aqueles que o detêm. Na previsão de alta de preços, práticas de entesouramento de moeda ou de depósitos em poupança reduzem-se, acelerando-se o consumo e a circulação monetária visto que o dinheiro perde o seu valor de troca a cada dia, e a pressão na velocidade de gasto em produtos e serviços impõe-se como consequência da compreensão generalizada de que o dinheiro não acompanha as altas.

Com o intuito de preservar certa liquidez dos negócios, mesmo em um ambiente de combinação entre alta de preços e depreciação da moeda, a política adotada pelos governos, conforme Friedman, pode estimular ainda mais a inflação quando recorre à emissão da moeda, tornando o dinheiro cada vez mais desvalorizado, à medida que essa emissão é recorrentemente utilizada. Seguindo a investigação a respeito dos motivos e da responsabilidade pela inflação, o economista chega a algumas interpretações interessantes. Para ele, em primeiro lugar, ainda que diversas razões sejam dadas para a análise da inflação, todas elas podem ser reduzidas a um único evento: a emissão da moeda acima da velocidade de circulação. De forma mais incisiva, Friedman afirma que a interpretação pluralística - que considera uma combinação de fatores para o surgimento da inflação, como investimentos governamentais, aumentos salariais ou financiamentos militares - funciona para aliviar a culpa do governo e de suas políticas econômicas inadequadas. Em segundo lugar, conforme Friedman, é um engodo a concepção de que é inevitável a inflação no processo de desenvolvimento econômico. Embora o economista constate que as altas inflacionárias apareçam mais pronunciadas na história da humanidade, ele não reconhece nisso um fato intrínseco à dinâmica dos mecanismos econômicos no decorrer dos tempos. Muito ao contrário disso, a inflação resulta das instituições monetárias e das medidas adotadas pelo governo. Inclusive, em algumas ocasiões, o próprio governo, para levantar fundos, pode promover, nocivamente, a inflação para viabilizar impostos sobre saldos monetários.

Enquanto Friedman discursou sobre a inflação como uma irregularidade derivada de incorreta política de emissão de moeda, os polemistas Still, com o vídeo The money masters (1996), e Joseph, com os vídeos Zeitgeist: the movie (2007), Zeitgeist: addendum (2008) e Zeitgeist: moving forward (2011), descreveram o processo inflacionário como um mecanismo de controle da ordem produtiva global por meio das corporações bancárias. Nesse momento, Still e Joseph realizaram uma tradução hiperbólica da teoria do estoque monetário tão divulgada por Friedman. Eles capturaram o cerne da explicação friedmaniana para a motivação inflacionária e elevaram os efeitos dela a uma condição generalizável de manipulação socioeconômica da produção e distribuição de capital numa dimensão global.

A razão tradutória da qual se serviram Still e Joseph é explicada de duas formas. Primeiro, em sua modalidade intersemiótica, ela é uma tentativa de massificação da análise econômica. Para isso, é necessário transportar essa análise do suporte dos livros (com menor capacidade de distribuição) para o suporte do vídeo (com maior escala de exibição para indivíduos ou grupos coletivos) 
e, posteriormente, ampliar sua capacidade de reprodução ao inserir o vídeo na internet. ${ }^{9}$ Segundo, em sua modalidade intralingual, a razão tradutória combate a terminologia por demais restritiva e elitista da área da Economia, que, tanto na perspectiva de Still como na de Joseph, mascara estratégias de preservação dos interesses de grupos dominantes com uma linguagem que inspira imparcialidade e exclusividade no trato de especialistas advindas de um pretenso cientificismo (dogmático) nas narrativas econômicas - mas que é fruto de uma formulação ideológica específica. Em meio à análise do setor financeiro, Joseph comenta que "a complexidade associada ao sistema financeiro é somente uma máscara criada para ocultar uma das estruturas mais socialmente estagnantes que a humanidade já tolerou" (ZEITGEIST, 2008). Igual opinião é dada por Still: ele denuncia a linguagem da área econômica como uma estratégia de ocultação do processo de emissão da moeda, afirmando como os bancos centrais, por representarem interesses privados e em cumplicidade com os governos, acabam por ser um dos maiores responsáveis pela inflação, ao invés de gerarem uma estabilidade anti-inflacionária.

\begin{abstract}
Sim, precisamos de bancos centrais. Não, não precisamos deles em mãos particulares. O esquema do banco central é realmente um imposto secreto. A nação vende títulos ao banco central para pagar coisas para as quais o governo não tem vontade política para subir os impostos para pagálos. Mas os títulos são comprados com o dinheiro que o banco central criou a partir do nada. Mais dinheiro em circulação faz o seu dinheiro valer menos. O governo consegue tanto dinheiro quanto precisa e o povo paga-o com a inflação. A beleza do plano é que nem 1 pessoa em 1000 possa imaginar isso, porque geralmente está escondido atrás de uma complexa linguagem econômica. (THE MONEY, 1996)
\end{abstract}

A razão tradutória, nesse sentido, é uma proposta de retirada dos jargões e da complexidade da linguagem técnica na área de análise econômica para que leigos possam compreender as causas e os efeitos do processo inflacionário. A característica hiperbólica dessa tradução deriva do fato de as narrações científicas de Still e Joseph irem além do que originalmente a teoria do estoque monetário de Friedman limita-se a afirmar. Na concepção de Still, esse "ir além" é uma ampliação da análise baseada no monetarismo de Friedman. Na concepção de Joseph, trata-se de uma contestação aos estudos econômicos como um todo e ao próprio Friedman, já que a limitação da análise friedmaniana é compreendida como estrategicamente ideológica. As traduções das narrativas científicas de Still e Joseph a respeito da teoria do estoque monetário também devem ser entendidas por hiperbólicas porque escapam do conceito de inflação como uma irregularidade a comprometer o sistema econômico para definirem o processo inflacionário como um instrumento de dominação integrado à economia praticada em escala mundial por bancos centrais, grandes corporações financeiras e grupos políticos.

${ }^{9}$ A internet, por consequência, gerou e multiplicou a modalidade de tradução interlingual quando grupos ou pessoas independentes do processo de produção dos vídeos, por iniciativa própria, iniciaram um processo de edição de legendas em canais do Youtube. A trilogia de Zeitgeist, dirigida por Peter Joseph, obteve tantas visualizações que conseguiu espaço de exibição na rede Netflix. 
Há também outros motivos para se considerarem como hiperbólicas as traduções de Still e Joseph: elas, ao agigantarem as causas e os efeitos da inflação como frutos de uma manipulação social e implicarem os bancos centrais nessa prática, desafiaram os contextos do discurso econômico do seu tempo. Krugman (2009) comenta que, entre os anos de 1985 e 2007, as disputas nos setores acadêmicos dos Estados Unidos entre os economistas interioranos, defensores da desregulamentação e dos mercados livres, e os litorâneos, novos keynesianos que se conformaram com as orientações monetárias do Fed, não geraram tensões, de modo a colocar em cheque, de forma tão radical, a política econômica estadunidense. Aliando tal constatação sobre os contextos de produção do saber econômico nos Estados Unidos aos Estudos de Linguagem, as narrativas de Still e Joseph também podem ser interpretadas como versões hiperbólicas quando confrontadas às versões mais encontradas nas universidades norte-americanas.

$\mathrm{Na}$ argumentação de Fiorin (2016), a fim de que as figuras de linguagem sejam compreendidas como operações enunciativas que enfatizam o sentido de algum componente do discurso, é preciso que tais tropos sejam reconhecidos dentro de um contexto mais abrangente. De forma similar à afirmação de Fiorin, Carrascoza (2003) declara que a investigação da hipérbole não pode ocorrer em uma situação que não considere o contexto de produção discursiva: o conhecimento de mundo é o que torna perceptível a extrapolação dos limites em uma cena discursiva.

Ademais, o próprio contexto de referência que originou e consolidou a teoria do estoque monetário, ou seja, os estudos de Friedman, quando ilustrado ao lado das discussões propostas por Still e Joseph, atesta o efeito hiperbólico das construções discursivas desses dois polemistas da área econômica. Conforme Friedman - o Nobel de Ciências Econômicas de 1976 - as causas e os efeitos da inflação podem ser explicitados, respectivamente, pelos seguintes trechos a seguir:

A maioria dos autores modernos atribui a inflação a causas bem diversas. Dizem que é o resultado de um desequilíbrio entre os investimentos que foram tentados e a poupança que a população estaria inclinada a fazer; da pressão salarial por parte dos empregados; da pressão por parte de patrões e empresários para um aumento dos lucros; pela inabilidade de conseguir que o aumento da produção de alimentos siga o mesmo ritmo da produção de outros artigos; e, assim por diante, sendo apontadas várias e diferentes causas. Ora, todas essas explicações podem, de certo modo, ser corretas. Se qualquer desses fatores contribuir para o aumento do estoque monetário, dará origem à inflação, mas, se não levar a um aumento do estoque monetário, não produzirá a inflação. (FRIEDMAN, 1978, p.27)

Os principais efeitos são: 1) A inflação torna dispendioso guardar dinheiro, levando as pessoas a efetuar depósitos menores do que fariam em outras circunstâncias. Com esse estado de coisas, o povo é levado a desperdiçar seus escassos recursos econômicos, e, ao tentar diminuir os depósitos, acaba despendendo mais tempo do que o desejável do ponto de vista da produtividade, verificando de perto sua posição de caixa, a fim de evitar a permanência, além de um certo período, de um saldo maior do que o estritamente necessário. 2) Os processos de reajustamento levam ao desperdício de parcos recursos nos meios contábeis. Tudo pode ser reajustado aos novos preços, mas os contadores terão que modificar os números nos livros, e as pessoas têm que calcular qual o ajuste necessário. 3) A economia monetária tende a restringir-se, porque o dinheiro é algo que vai gradualmente perdendo o valor, e, portanto, o povo procura guardar apenas uma parte relativamente pequena daquilo que recebe. Criase, então, forte prevenção contra a expansão da economia monetária, nas áreas onde ela não existe. (FRIEDMAN, 1978, p.73-74) 
Friedman, em suas explicações, busca limitar a causa da inflação à elevação do estoque monetário e, praticamente, evita explanações maiores que possam promover disparos a essa emissão de crédito acima da capacidade de bens e serviços. Dentro da perspectiva friedmaniana, o que há é uma sugestão de uma maior eficácia na análise do processo inflacionário quando se defende a concentração dos estudos econômicos a partir do fenômeno do aumento de estoque de moeda. Em relação aos efeitos da inflação, Friedman restringe a sua investigação sobre a inflação à esfera do gasto e do desperdício de recursos. Igualmente, o economista evita uma análise mais ampla das consequências sociais do ritmo inflacionário. Para ele, a inflação acarreta depósitos menores, pois o dinheiro é um ativo que se desvaloriza frente aos valores de consumo; a inflação faz desperdiçar recursos nos processos de reajustamento de valores em meios contábeis; e a inflação enfraquece um acúmulo de capital suficiente para o investimento em áreas de retorno para a economia de um país.

Mesmo sendo derivada da teoria do estoque monetário, a análise de Joseph sobre as causas e os efeitos do processo inflacionário atinge dimensões sociais em escalas bem maiores que a aplicação dos estudos de Friedman. Para Joseph, a causa da inflação está associada ao fato de a emissão de moeda sustentar a dívida dos governos e dos cidadãos com as grandes corporações bancárias. O valor da dívida e dos juros advindos dela, por ser maior que o suprimento de dinheiro disponível, estimula cada vez mais a emissão de moeda, que se desvaloriza por meio do processo inflacionário, ampliando a dívida e a necessidade de mais dinheiro com tendência à depreciação. A inflação, portanto, como efeito, é um componente do círculo vicioso de desvalorização monetária como instrumento de dominação social exercida por membros de gigantescas instituições financeiras. Por meio da inflação e do risco de falência, segundo Joseph, criam-se uma espécie de escravidão contemporânea no plano dos indivíduos, que ficam pressionados pela cobrança das contas e pela perda contínua do valor de compra, e até mesmo uma subserviência de países inteiros, que enfrentam dificuldades em pagar os juros dos empréstimos advindos de instituições internacionais de créditos (associadas aos interesses corporativos transnacionais).

Na visão de Still, a continuidade da tendência inflacionária na economia estadunidense deve-se, principalmente, a dois fatores: a) por ser o conselho do Federal Reserve constituído, em sua maioria, de membros que representam os interesses das grandes corporações bancárias, as decisões monetárias do Fed não podem representar a vontade democrática daqueles que elegeram governos ou não podem objetivar políticas econômicas de cancelamento da dívida nacional; e b) a reserva fracionária bancária, como estratégia elaborada pelo Fed para a elevação de suprimento bancário de moedas por meio da política de concessão de empréstimos a números muito acima do aporte de depósitos em banco, multiplica a inflação e, por consequência, a dívida nacional em razões exponenciais. Como efeitos da dívida e do processo inflacionário, tem-se a entrega do comando econômico dos Estados Unidos às grandes corporações bancárias, que, para cumprirem seus objetivos de maior concentração econômica, podem promover, ciclicamente, depressões advindas de abruptas contenções na política de concessão de créditos 
para baratear empresas, bens e resgatá-los por meio do processo de endividamento gerado. Se forem levados em consideração os argumentos de Still, nos anos 90, de que a depressão econômica é uma forma astuciosamente pensada pelos fortes agrupamentos bancários para se apropriarem de recursos públicos ou privados, o colapso de 2008 pode ser lido como uma oportunidade de resgate de trilhões de dólares dos contribuintes estadunidenses ou de compra depreciada de negócios nos setores privados afetados pela crise.

No contexto em que surgiram tais argumentações de Still, em 1996, e de Joseph, em 2007, tanto os setores de discussão de análise econômica como a própria teoria do estoque monetário consolidada por Friedman não previam nem tais causas nem tais efeitos para o processo inflacionário. A tradução do estoque monetário por Still e Joseph surge bruscamente e destoante dos contextos de referência e dos que a circundam. A tradução, portanto, ocorre em um momento em que sua realização promove choque nesses contextos; e ela, por eles, acaba, consequentemente, sendo interpretada como um exagero. Esse lançamento brusco de argumento, sem quaisquer preparações ou justificações que permitissem uma enunciação compatível com tais contextos, caracteriza, segundo Perelman e Olbrechts-Tyteca (2005), a hipérbole.

Conforme Charaudeau e Maingueneau (2008), a finalidade do excesso ou da desmedida provocados pela hipérbole não seria de enganar, mas de apontar para uma verdade instalada pelo discurso - pelo inicialmente inacreditável ou subitamente exagerado, deve-se observar aquilo que escapa de nossa razão habitual. A tradução hiperbólica da teoria do estoque monetário, por Still e Joseph, não somente choca os contextos de discussão sobre análise econômica como também os denuncia como cenários de cumplicidade.

Essa tradução toma as interpretações de Friedman como pistas, impondo uma releitura radical que serve de base para o ativismo econômico exercido por Still e Joseph. A constatação de Friedman de que as altas nos preços são mais recorrentes e de que não pertencem ao desenvolvimento econômico (mas sim às decisões das instituições monetárias) é relida por tais ativistas econômicos como se fosse uma instrumentação lógica abrangente de exploração socioeconômica. Ademais, na avaliação friedmaniana de que uma parte relativamente pequena de moeda é guardada nas economias domésticas por causa da perda gradual do valor do dinheiro, Still e Joseph reconheceram uma motivação para o exacerbado consumismo contemporâneo baseado, ao mesmo tempo, na pressão inflacionária e no risco da escassez.

Interessante notar como os estudos de Friedman sobre o processo inflacionário, geralmente associados a uma determinada ala conservadora de economistas, atingiram, por meio da hipérbole efetivada por esses ativistas, uma carga semântica libertária do padrão de lógica da emissão e distribuição monetárias. E isso se deve predominantemente pela avaliação que ambos fazem da economia bancária estadunidense. Tanto Still como Joseph verificam que a economia bancária dos Estados Unidos depende de um mercado multidirecional e variável de inovações que permita uma elevação contínua de consumidores que não cesse os pedidos de liberação de crédito a estimular, cada vez mais, a 
emissão de moedas e títulos do tesouro. Tal conclusão toma como modelo o papel do Federal Reserve nos Estados Unidos. Caracterizado como uma corporação internacional privada que detém o controle da emissão do dólar, o Federal Reserve libera o crédito em moeda tal como um empréstimo realizado aos Estados Unidos mediante promessas de pagamento pela troca em títulos do tesouro nacional e com juros embutidos. Para pagar os juros da dívida pública advindos, em boa parte, do empréstimo do Federal Reserve, políticos estimulam a elevação de impostos sobre serviços e produtos. Entretanto, os aumentos de impostos não podem estancar a aceleração desenfreada da produção e do consumo, pois esse é o combustível necessário para ativar uma circulação monetária maior e, consequentemente, uma necessidade de mais emissão de moeda. É por isso que, para não travar a liquidez do mercado, ocorre uma facilitação de empréstimos pelas corporações bancárias por meio da Mecânica Moderna do Fed, em que a quantidade emprestada reflete uma proporção gigantesca em relação aos depósitos garantidos em banco. Essa diferença exacerbada de proporção entre empréstimos e depósitos chega a afetar investimentos e as dívidas acabam por preponderar acima do capital circulante. Tais liberações de créditos implicam a necessidade de novas emissões de dólar e, a partir delas, novos juros de empréstimo à dívida pública dos Estados Unidos são gerados com o efeito do custo inflacionário repassado para a população trabalhadora e consumidora. Um círculo vicioso, portanto, constitui-se desse movimento que acaba por elevar gradualmente a dívida pública dos Estados Unidos e as dívidas de empréstimos para pessoas físicas: quanto mais dinheiro é emitido, menor será o seu valor por causa do processo inflacionário e quanto menor é o valor do dinheiro, maior será a exigência de sua emissão para comportar o aumento dos novos custos. O resultado disso é a acumulação de juros da dívida pública de modo que ela se torna impagável ao mesmo tempo em que a liberação de crédito aprisiona boa parte de consumidores endividados.

Nessa perspectiva, Bauman (2008), em seu livro Vida para consumo, ironiza as escolhas da política econômica dos Estados Unidos, que se reflete como um modelo de economia robusta a influenciar outros países e as formas de gerenciamento monetário do cidadão comum. O elogio ao consumismo com a paralela exponencialização da dívida, embora aponte para o precipício de uma inevitável crise, é tido por referência de sucesso e de segurança na área econômica.

O estímulo da dívida aos consumidores, na visão dos dois ativistas da economia, realiza um padrão que, mais propriamente, Joseph denominou de "escravidão contemporânea". O aprisionamento do cidadão no débito a sempre ameaçar ou reduzir o poder de compra obriga-o, contraditoriamente, a contrair novos empréstimos e, nos ciclos de oportunas reduções de crédito, a inadimplência, a falência e o risco de desemprego levam os endividados a venderem suas posses por preços irrisórios em negociações que, direta ou indiretamente, alimentam os lucros das corporações bancárias. Ocorrendo o resíduo dos débitos e o retorno dos juros, o trabalhador endividado pode enfrentar nova crise financeira com uma nova rodada de redução de seus bens. Além disso, por causa da própria dívida, o trabalhador, temendo o desemprego, também fica mais conformado com baixos salários e com o enfraquecimento dos seus direitos. Por fim, a associação entre 
os meios de facilitação e agigantamento da dívida e a louvação ao consumismo constroem três fenômenos indissociáveis: a elevação da carga de trabalho advinda dos sacrifícios do cidadão comum para preservar seu poder de compra ao mesmo tempo em que se vê ameaçado com a demissão e com o enfraquecimento das unidades de salário, o estímulo ao desperdício para que a velocidade do consumo mantenha-se elevada e a irrelevância social dos serviços de modo que a multiplicação na função do trabalho possa sustentar o volume dos empréstimos do cidadão comum e, ao mesmo tempo, possa ser operada por qualquer mão de obra de fácil contratação e dispensa.

Ainda que Still e Joseph possuam muitas interpretações em comum a respeito da economia bancária e imprimam a hipérbole para reler a teoria do estoque monetário de Friedman, as conclusões a que chegam esses dois ativistas são diametralmente opostas. Still explica os ciclos econômicos considerando que as crises e o fenômeno inflacionário foram induzidos em meio à consolidação das grandes instituições bancárias no decorrer da história do capital por meio da estratégia de encharcamento de crédito seguida de contínua retração de moeda, portanto o que deve ser combatido é o imenso poder das corporações bancárias. A explicação de Still avalia as considerações de Friedman como as mais pertinentes no sentido de defender uma economia em que se estabeleça um nível de concorrência adequado, com instituições comerciais e financeiras de pequeno e médio portes e sem os conglomerados bancários com um vasto poder para ditar normas contratuais no universo das finanças. Além disso, Still, ao analisar a crescente dívida pública dos Estados Unidos e a contínua queda do poder de compra do contribuinte estadunidense, recomenda, como uma das formas de reorganização das contas nesse país, que o controle da emissão do dólar retorne ao Estado. No caso de Joseph, mesmo que parta de Friedman, é evidente a crítica generalizável de tal ativista à ciência econômica desde Smith, que serve para sofisticar cálculos e mascarar a perversidade dos lucros. Para Joseph, Friedman é mais um cúmplice do sistema monetário e o que precisa ser combatido é a própria organização social em torno da lógica da troca e do acúmulo da moeda. Longe da nocividade de grande parte do pensamento econômico ao pensar o lucro dissociável do elemento humano ou do meio-ambiente, o movimento Zeitgeist, criado por Joseph, acaba sendo uma proposta de discussão a respeito de uma sociedade não monetarista que se reorganizasse por meio do equilíbrio dos recursos naturais.

\section{CONSIDERAÇÕES FINAIS}

Segundo os ensinamentos de Fiorin (1998), em Linguagem e Ideologia, não somente as representações ideológicas são materializadas pelo discurso como também o conhecimento, fruto de organização discursiva, compromete-se com interesses sociais. Nesse sentido, Fiorin torna claro que a neutralidade não é resultado de uma adequada aplicação científica; o discurso da imparcialidade no campo da ciência deriva, em verdade, da força ideológica dos grupos sociais dominantes. Levar isso 
em consideração é reconhecer que a prática retórica é o centro da produção do saber científico. Quando os estudos linguísticos, com essa perspectiva, aproximam-se da análise econômica, o tipo de investigação interdisciplinar que pode surgir a partir daí tanto potencializa uma como outra área. Nas ciências econômicas, o estudo a respeito da intenção discursiva, como uma vertente diferente da análise da sequência monetária ou do planejamento para a maximização dos lucros, aparece como um instrumento necessário para conter a nocividade da hegemonia interpretativa nessa área. É preciso compreender a camuflagem ideológica que cerca as teorias econômicas vigentes, a fim de que uma nova cegueira ou um surto de confiança não possam promover uma crise como a que aconteceu em 2008. Nas ciências linguísticas, o alargamento do seu instrumental teórico para a área da economia possibilita uma aplicabilidade que amplia a capacidade de modificar a dimensão social associada aos resultados das discussões da análise econômica. Reconhecer e expor as intenções dos discursos na área da ciência econômica, com o auxílio da teoria linguística, desmonta as estratégias incutidas neles.

Em outro livro, Figuras de retórica, Fiorin (2016), alegando ocorrer uma retoricidade geral na linguagem, argumenta que os critérios de verdade ou de objetividade priorizados em alguns discursos são efeitos de sentido. Desse modo, o estudo aprofundado da retórica permite reconhecer os mecanismos coercitivos por trás da verdade e como a construção da noção de verdade e de objetividade dá-se pelo recurso da verossimilhança demasiadamente apoiada pela força persuasiva. A partir disso, uma boa maneira de buscar traços retóricos nos discursos da área econômica é investigar a construção desses por meio das figuras de linguagem. Ainda que reservemos a concepção das figuras de linguagem como recursos poéticos, é inevitável a associação entre retórica e poética. Para Kothe, a poética é uma parte mais disfarçada e, desse modo, mais eficiente da retórica:

A poética é uma retórica, mesmo quando expressamente declara que não pretende persuadir. A retórica é mais direta (e, portanto, mais honesta) em seu desejo de manipular vontades, alterando ou reforçando convicções; nesse processo, a poética é mais sutil, e assim mais eficaz. (KOTHE, 1986, p.89)

A partir de tais considerações, pode-se afirmar que a escolha das figuras de linguagem no âmbito do discurso econômico reflete o posicionamento ideológico dos próprios enunciadores. No caso de Taleb, a alegoria do cisne negro é uma figura de linguagem que abarca a área econômica tornando-a como uma especificidade da epistemologia contemporânea. Como teórico da incerteza, com uma vida acadêmica consolidada a partir de tais estudos, a crítica de Taleb enfatiza a fragilidade dos sistemas de previsão econômica como parte de uma reforma maior em relação ao sistema de conhecimento hodierno. Nesse sentido, a alegoria de Taleb acaba por isentar a responsabilidade do discurso técnico-científico da área da economia, assim como tira dele a possibilidade de resolução de um problema que lhe é maior e que somente será resolvido se alterados os parâmetros de análise da causalidade recorrente. Taleb direciona o assunto da crise econômica para a área da epistemologia - em que se reconhece a posse maior do próprio filósofo da incerteza. 
No caso de Minsky, o recurso da metonímia condiz com o seu posicionamento moderado em relação às formas de financiamento das unidades econômicas. A metonímia permite com que Minsky fale de uma parte nociva da política de empréstimos contemporânea sem que seja feita uma crítica radical da totalidade das operações financeiras. Com igual estratégia de colocação da metonímia, o economista apresenta a geração das unidades especulativas ou Ponzi como um fragmento indissociável do capitalismo financeiro. Entretanto, comenta que as escolhas das instituições com responsabilidade na política econômica podem promover instabilidade generalizada ao facilitar o agigantamento de tais unidades. Minsky preserva sua crença nos sistemas atuais do capitalismo financeiro que mantêm a estabilidade das unidades hedge, mas protesta em relação ao contágio da especulação sem qualquer princípio regulatório quanto à política de financiamentos.

O uso da hipérbole por Still torna-se apropriado, pois, ao atribuir uma dimensão mais colossal às consequências negativas e inflacionárias da teoria do estoque monetário, pôde-se alterar a orientação de ajustamento da política monetária oriunda de Friedman para o de combate frontal ao controle da emissão de dinheiro. Em relação a Joseph, a crítica torna-se ainda mais radical quando ele contrapõe-se à própria necessidade de armazenamento ou de troca da lógica monetarista. O efeito da hipérbole como demonstração de distância de uma realidade acreditável no discurso de tais ativistas da área econômica associa-se a uma postura que precisa desvelar o entendimento padrão do discurso econômico e apontar, por proveitoso exagero ou defeito, uma realidade econômica trágica, mas disfarçada de normalidade cotidiana.

\section{REFERÊNCIAS}

BAUMAN, Z. Vida para consumo: a transformação das pessoas em mercadoria. Rio de Janeiro: Jorge Zahar Ed., 2008.

CARRASCOZA, J. A redação publicitária: estudos sobre a retórica do consumo. São Paulo: Futura, 2003.

CHARAUdeaU, P.; MAINGUENEAU, D. Análise de textos de comunicação. São Paulo: Cortez, 2008 .

CONCEIÇÃO, D. N. Nota técnica introdutória ao artigo "A hipótese da instabilidade financeira", de Hyman P. Minsky. Oikos. Rio de Janeiro, v.8, n 2., 2009, pp. 303-313.

ESCARDUÇA, C. Hipérbole. In: CEIA, C. (coord.). E-dicionário de termos literários. Lisboa: CETAPS. 2005. Disponível em: <http://edtl.fcsh.unl.pt>. Acesso em: 05 set. 2016.

FIORIN, J. L. Figuras de retórica. São Paulo: Contexto, 2016.

FIORIN, J. L. Linguagem e ideologia. São Paulo: Editora Ática.

FRIEDMAN, M. Inflação: suas causas e consequências. Rio de Janeiro: Expressão e Cultura, 1978. 
HANK: Cinco anos depois do colapso. Direção de Joe Berlinger. Edição de Brett Mason. Elenco: Henry Paulson e Wendy Paulson. Radical Media / Bloomberg Businessweek Films. Estados Unidos: 2013. [DVD]. (86 min), colorido.

JAKOBSON, R. Linguística e comunicação. São Paulo: Editora Cultrix, 2003.

KEYNES, J. M. A teoria geral do emprego, do juro e da moeda. São Paulo: Atlas, 1982.

KOTHE, F. R. A alegoria. São Paulo: Editora Ática, 1986.

KRUGMAN, P. Como os economistas puderam errar tanto? Econômica. Rio de Janeiro, v.11, nº 2., 2009, pp.15-35.

LAKOFF, G.; JOHNSON, M. Metáforas da vida cotidiana. Campinas-SP: Mercado de Letras; São Paulo: EDUC, 2002.

LEITURAS de O médico e o monstro: alegoria e metáfora. Entrevista com Glória Palma. Direção e Produção: Ilona Messenberg Szabó. 8'11". Disponível em: <https://www.youtube.com/ watch?v=7GZ2Qa8STdU>. Acesso em: 05 set. 2015.

MINSKY, H. P. A hipótese da instabilidade financeira. Oikos. Rio de Janeiro, v.8, n 2., 2009, p.314320.

PERELMAN, C.; OLBRECHTS-TYTECA, L. Tratado da argumentação: a nova retórica. São Paulo: Martins Fontes, 2005.

PINTO, S. R. Metonímia. In: CEIA, C. (coord.). E-dicionário de termos literários. Lisboa: CETAPS. 2005. Disponível em: <http://edtl.fcsh.unl.pt>. Acesso em: 05 set. 2016.

REBOUL, O. Introdução à retórica. São Paulo: Martins Fontes, 2001.

SMITH, A. A mão invisivel. São Paulo: Penguin Classics; Companhia das Letras, 2013.

TALEB, N. N. A lógica do cisne negro: o impacto do altamente improvável. Rio de Janeiro: BestSeller, 2008.

THE MONEY masters. Direção (roteiro e comentários) de William T. Still. Produção: Patrick Carmack. Estados Unidos: 1996. [DVD]. (210 min), colorido.

ZEITGEIST, the movie. Direção (roteiro e comentários) de Peter Joseph. Estúdio GMP. Estados Unidos: 2007. [DVD]. (119 min), colorido.

ZEITGEIST: addendum. Direção de Peter Joseph. Zeitgeist Films. Comentaristas: Peter Joseph, Jacque Fresco, Roxane Meadows, John Perkins e outros. Estados Unidos: 2008. [DVD]. (123 min), colorido.

ZETGEIST: moving forward. Direção (roteiro e produção) de Peter Joseph. Estúdio GMP LLC. Comentaristas: Peter Joseph, Jacque Fresco, Roxane Meadows, Ashton Cline, Robert Sapolsky, Adrian Bowyer, Colin J. Campbell, James Gilligan, Gabor Maté e outros. Estados Unidos: 2011. [DVD]. (162 min), colorido. 